\title{
- \\ Impact of COVID-19 on education, health and lifestyle behaviour of Brazilian urology residents
}

José Antonio Prezotti ${ }^{1}$, João Victor T. Henriques ${ }^{1}$, Luciano A. Favorito ${ }^{2}$, Alfredo F. Canalini ${ }^{3}$, Marcos G. Machado ${ }^{1}$, Thulio B. V. Brandão ${ }^{1}$, Akemi M. V. Barbosa ${ }^{1}$, Julyana K. M. Moromizato ${ }^{1}$, Karin M. J. Anzolch ${ }^{4}$, Roni de C. Fernandes ${ }^{5}$, Fransber R. A. Rodrigues ${ }^{6}$, Carlos H. S. Bellucci ${ }^{1}$, Caroline S. Silva ${ }^{7}$, Antonio Carlos L. Pompeo ${ }^{8}$, Jose de Bessa Jr. ${ }^{7}$, Cristiano M. Gomes ${ }^{1}$

${ }^{1}$ Divisão de Urologia, Faculdade de Medicina da Universidade de São Paulo - FMUSP, São Paulo, SP, Brasil; ${ }^{2}$ Unidade de Pesquisa Urogenital, Universidade do Estado do Rio de Janeiro - UERJ, Rio de Janeiro, Rio de Janeiro, RJ, Brasil; ${ }^{3}$ Disciplina de Urologia, Universidade do Estado do Rio de Janeiro - UERJ, Rio de Janeiro, Rio de Janeiro, RJ, Brasil; ${ }^{4}$ Serviço de Urologia, Hospital Moinhos de Vento, Porto Alegre, RS, Brasil; ${ }^{5}$ Faculdade de Ciências Médicas, Santa Casa de São Paulo, São Paulo, SP, Brasil; ${ }^{6}$ Divisão de Urologia, Universidade de Brasília - UNB, Brasília, DF, Brasil; ${ }^{7}$ Departamento de Cirurgia, Universidade Estadual de Feira de Santana, Feira de Santana, BA, Brasil; ${ }^{8}$ Disciplina de Urologia, Universidade Federal do ABC - UFABC, Santo André, SP, Brasil

\section{ABSTRACT}

Objectives: To evaluate the impact of COVID-19 on clinical and surgical practice, educational activities, health and lifestyle behavior of Brazilian urology residents.

Materials and Methods: A web-based survey was sent to 468 Brazilian urology residents from postgraduate years (PGY) 3 to 5 to collect data on clinical practice and training after 4 months of COVID-19. We also assessed health-related and behavior changes, rate of infection by SARS-CoV-2, deployment to the front line of COVID-19, residents' concerns, and access to personal protective equipment (PPE).

Results: Massive reductions in elective and emergency patient consultations, diagnostic procedures and surgeries were reported across the country, affecting PGY 3 to 5 alike. Most in-person educational activities were abolished. The median damage to the urological training expected for 2020 was 6.0 [3.4 -7.7], on a scale from 0 to 10, with senior residents estimating a greater damage $(\mathrm{P}<0.001)$. Educational interventions developed included online case-based discussions, subspeciality conferences and lectures, and grand rounds. Most senior residents favored extending residency to compensate for training loss and most younger residents favored no additional training $(\mathrm{p}<0.001)$. Modifications in health and lifestyle included weight gain (43.8\%), reduced physical activity (68.6\%), increased alcoholic intake (44.9\%) and cigarette consumption (53.6\%), worsening of sexual life (25.2\%) and feelings of sadness or depression (48,2\%). Almost half were summoned to work on the COVID-19 front-line and 24.4\% had COVID-19. Most residents had inadequate training to deal with COVID-19 patients and most reported a shortage of PPE. Residents' concerns included the risk of contaminating family members, being away from residency program, developing severe COVID-19 and overloading colleagues.

Conclusions: COVID-19 had a massive impact in Brazilian urology residents' training, health and lifestyle behavior, which may reflect what happened in other medical specialties. Studies should confirm these findings to help developing strategies to mitigate residents' losses.

\section{ARTICLE INFO}

José Antonio Prezotti

https://orcid.org/0000-0001-5359-455X

Keywords:

Surveys and Questionnaires;

Education, Medical; COVID-19

Int Braz J Urol. 2021; 47: 753-76

Submitted for publication: January 05, 2021

Accepted after revision:

January 09, 2021

Published as Ahead of Print: March 05, 2021 


\section{INTRODUCTION}

COVID-19 led to profound changes in the medical scenario worldwide, including a massive reduction of face-to-face medical consultations and suspension or postponement of elective surgical procedures $(1,2)$. In addition, it caused a redeployment of health professionals to work at the front line caring for infected patients $(3,4)$. Urological practice was immensely affected. A recent survey conducted among Brazilian urologists showed an enormous reduction of patient visits, elective, and emergency surgeries, as well as a drastic reduction of income all over the country (5).

Urology residency programs have been facing problems that include not only the major cutback of residents' participation in medical visits and surgeries, but also the reduction of educational and scientific activities (3, 4, 6, 7). Moreover, residents represent a large component of the workforce at various health facilities and in many hospitals they have become critical at the front line of care for patients with COVID-19 $(3,4)$.

Urology residents have dealt with major challenges not only in terms of medical training, but also regarding their personal lives, health and well-being. Social distancing, fear of contamination and/or transmitting the disease to relatives and reduction of income are some of the problems and concerns affecting medical residents. Consistent with this, a significant proportion have been experiencing anxiety and depression disorders $(8,9)$.

While the pandemic numbers went down in many countries for some time, a second wave is effective in many regions (US, Europe) (10, 11). Some countries like Brazil, Argentina and India persist with high COVID-19 infection rates $(10,12)$. As a result, a significant detrimental impact on urology training has occurred and should remain indefinitely in many countries.

Considering the unique behavior of $\mathrm{CO}$ VID-19 in Brazil, we hypothesized that Brazilian urology residents were severely impacted in their training, health and personal lives and that the impact on urology training was more severe for senior residents.

\section{MATERIALS AND METHODS}

This study was approved by the Research Ethics Committee of the University of Sao Paulo School of Medicine (project number CAPPESQ 13029/2020) and informed consent was obtained from all participants.

An electronic survey was emailed to 468 eligible urology residents from postgraduate years (PGY) 3 to 5 registered in the Brazilian Society of Urology, with no incentives for completion. The first e-mail inviting the residents to participate was sent on June/11/2020 and data collection was closed on June/19/2020, when the whole country had lived the third month of social distance officially recommended by state and federal sanitary authorities

The primary goal was to collect data on resident's clinical practice and urological training since the beginning of COVID-19. The survey included an assessment of socio-demographic, clinical practice, educational, health-related and behavior parameters. The invitation e-mail contained a link to a 39 questions, web-based survey see (Supplementary Questionnaire in Appendix). Most questions were closed-ended, multiple choice. One question evaluated the subjective degree of damage to the urological training based on the residents' educational expectations for 2020. It was evaluated with a visual analog scale ranging from zero to ten, in which "zero" was the least possible educational damage.

We also investigated alternative educational activities that were implemented by urology residency programs such as web meetings, web conferences and online education programs.

We investigated the number of residents that were infected by SARS-CoV- 2, the deployment to the front line of COVID-19 and other aspects associated with residents' fears and concerns, and access to personal protective equipment. Changes in health parameters and behaviors such as body weight, physical activities, alcohol and tobacco consumption and sexual life were also evaluated.

Finally, based on the continental dimensions of Brazil and the varying incidence rates of COVID-19 and stages of economic opening, we compared data from states that were among the lowest incidence rates at the time of the survey (Minas Gerais, Goias, Rio Grande do Sul and Parana) with those among the 
highest incidence states (São Paulo and Rio de Janeiro) (12).

\section{Data collection and Statistical analyses \\ Data were initially elaborated using} Survey Monkey ${ }^{\circledR}$ software online. Quantitative variables were expressed as medians and interquartile ranges, while qualitative variables were expressed as absolute values, percentages, or proportions. Student's t or ANOVA was used to compare continuous variables.

Categorical variables were compared using the Chi-squared or Fisher's exact test. Associations were described as Odds Ratios with respective confidence intervals. All tests were 2 -sided and a $\mathrm{p}$ value $<0.05$ was considered statistically significant. GraphPad Prism, version 8.0.4, San Diego-CA, USA, was used for data analysis

\section{RESULTS}

A total of 275 (58.7\%) subjects completed the survey. Most respondents (90.5\%) were men, and the median age was 30 years [28-31]. Ninety (32.7\%) participants were from PGY 3, 90 (32.7\%) from PGY 4 and 95 (34.6\%) from PGY 5. The distribution of participants was proportional to the actual distribution of Brazilian urology residents across the country's five different geographic regions (supplementary material; $p=0.632$ ).

Impact of Covid on residents' clinical and surgical activities

Major reductions in elective and emergency patient consultations, diagnostic procedures and surgeries were reported by residents from all states. Similar reductions of elective visits $(p=0.398)$, emergency visits (0.092), minor surgeries $(p=0.344)$, major surgeries $(p=0.107)$, and diagnostic procedures $(p=0.159)$ were observed across residents from PGY 3, 4 and 5. There were no differences between states with highest vs lowest incidence of COVID-19 (Table-1).

\section{Impact on educational activities}

The impact of COVID-19 on urology residents' educational program and scientific activities is shown in Table 2, with major reductions in general urology and subspecialty meetings in addition to in-person practical educational activities.

The median estimated damage to the urological training expected for 2020 in a scale from 0 to 10 was 6.0 [3.4-7.7]. PGY 4 and 5 residents estimated a greater damage for their training than PGY 3 $(\mathrm{P}<0.001$; Figure-1). Residents living in states with highest incidence of COVID-19 did not differ from those living in lowest incidence states $(\mathrm{p}=0.777)$.

\section{Educational initiatives during the pandemic}

Since the start of COVID-19 pandemic, educational interventions developed by residency programs to compensate for the deprivation of training were frequent and included: case based discussions, journal club web meetings, subspeciality web conferences, pre-recorded video lectures, online courses and online general urology department grand rounds (Table-2). Asked about their preferred educational activities, online courses and lectures were chosen as their favorite instructional method by $48.1 \%$ of the urology residents, case-based discussions web meetings by $38.2 \%$ and didactic podcasts by $14.6 \%$.

Regarding measures that should be adopted to compensate for the loss of their urological training in 2020, 147 (53.6\%) suggested postponing the finishing date of the residency program, 57 (20.8\%) suggested additional training in specific subspecialties and 70 (25.6\%) required no compensation. Urology residents' perceptions regarding the need for additional training were significantly different according to postgraduate year, with senior residents favoring extending residency for some months and younger residents favoring no additional training $(\mathrm{p}<0.001$; Figure-1).

\section{Impact on residents's health}

The impact of COVID-19 on urology residents' health is shown in Table-3. A total of 148 (53.8\%), 54 (19.6\%) and 73 (26.6\%) considered themselves healthy, moderately healthy and not healthy, respectively. Weight gain was reported by $43.8 \%$ and $68.6 \%$ reported a reduction of physical activities. Of the $28(11.4 \%)$ participants who declared being tobacco smokers, cigarette consumption increased for $15(53.6 \%)$ and decreased for 2 (7.1\%) residents. Among the participants who drink alcoholic bevera- 
Supplementary Material: Geographic regions in Brazil and state distribution of the $\mathbf{2 7 5}$ participants of the survey

\begin{tabular}{|c|c|c|}
\hline Geographic region / State & $N^{*}(\%)$ & Actual state distribution ${ }^{\star *}(\%)$ \\
\hline Southeast & $180(65.4)$ & $316(67.3)$ \\
\hline São Paulo & $102(37.1)$ & $188(40.1)$ \\
\hline Minas Gerais & $26(9.5)$ & $57(12.1)$ \\
\hline Rio de Janeiro & 48 (17.4) & $64(13.6)$ \\
\hline Espirito Santo & $4(1.4)$ & $7(1.5)$ \\
\hline South & $24(8.7)$ & 48 (10.1) \\
\hline Paraná & $12(4.3)$ & $28(5.9)$ \\
\hline Rio Grande do Sul & $11(4.0)$ & $14(2.9)$ \\
\hline Santa Catarina & $1(0.4)$ & $6(1.3)$ \\
\hline Northeast & $42(15.3)$ & $68(14.4)$ \\
\hline Alagoas & $0(0.0)$ & $0(0.0)$ \\
\hline Bahia & $12(4.3)$ & $15(3.2)$ \\
\hline Ceara & $12(4.3)$ & $17(3.5)$ \\
\hline Maranhão & $0(0.0)$ & $0(0.0)$ \\
\hline Paraíba & $0(0.0)$ & $0(0.0)$ \\
\hline Pernambuco & $12(4.3)$ & $30(6.4)$ \\
\hline Piauí & $0(0.0)$ & $0(0.0)$ \\
\hline Rio Grande do Norte & $6(2.4)$ & $6(1.3)$ \\
\hline Sergipe & $0(0.0)$ & $0(0.0)$ \\
\hline Center-West & $24(8.7)$ & $33(7.1)$ \\
\hline Federal District & $8(2.9)$ & $13(2.8)$ \\
\hline Goias & $11(4.0)$ & $9(1.9)$ \\
\hline Mato Grosso & $2(0.7)$ & $3(0.7)$ \\
\hline Mato Grosso do Sul & $3(1.1)$ & $8(1.7)$ \\
\hline North & $5(1.8)$ & $6(1.2)$ \\
\hline Acre & $0(0.0)$ & $0(0.0)$ \\
\hline Amapá & $0(0.0)$ & $3(0.6)$ \\
\hline Amazonas & $4(1.4)$ & $3(0.6)$ \\
\hline Para & $0(0.0)$ & $0(0.0)$ \\
\hline Rondônia & $0(0.0)$ & $0(0.0)$ \\
\hline Roraima & $0(0.0)$ & $0(0.0)$ \\
\hline Tocantins & $1(0.4)$ & $0(0.0)$ \\
\hline
\end{tabular}

* Urology residents who participated in the survey

** Official state distribution of urology residents who received invitation for the survey 
Table 1 - Impact of COVID-19 on Brazilian urology residents' clinical practice.

\begin{tabular}{|c|c|}
\hline Practice activity & $\%$ \\
\hline \multicolumn{2}{|l|}{ Elective patient visits } \\
\hline Remained stable & 5.9 \\
\hline Decreased up to $25 \%$ & 8.7 \\
\hline Decreased 25 to $50 \%$ & 20.7 \\
\hline Decreased 50 to $75 \%$ & 28.0 \\
\hline Decreased $>75 \%$ & 36.7 \\
\hline \multicolumn{2}{|l|}{ Emergency patient visits } \\
\hline Remained stable & 31.3 \\
\hline Decreased up to $25 \%$ & 20.0 \\
\hline Decreased 25 to $50 \%$ & 25.8 \\
\hline Decreased 50 to $75 \%$ & 12.4 \\
\hline Decreased $>75 \%$ & 10.5 \\
\hline \multicolumn{2}{|l|}{ Minor surgeries* } \\
\hline Remained stable & 4.4 \\
\hline Decreased up to $25 \%$ & 9.1 \\
\hline Decreased 25 to $50 \%$ & 8.0 \\
\hline Decreased 50 to $75 \%$ & 13.8 \\
\hline Decreased $>75 \%$ & 64.7 \\
\hline \multicolumn{2}{|l|}{ Endoscopic surgeries** } \\
\hline Remained stable & 14.2 \\
\hline Decreased up to $25 \%$ & 13.9 \\
\hline Decreased 25 to $50 \%$ & 25.9 \\
\hline Decreased 50 to $75 \%$ & 17.1 \\
\hline Decreased $>75 \%$ & 28.9 \\
\hline \multicolumn{2}{|l|}{ Major surgeries*** } \\
\hline Remained stable & 16.8 \\
\hline Decreased up to $25 \%$ & 13.5 \\
\hline Decreased 25 to $50 \%$ & 22.3 \\
\hline Decreased 50 to $75 \%$ & 18.9 \\
\hline Decreased $>75 \%$ & 28.5 \\
\hline \multicolumn{2}{|l|}{ Diagnostic procedures } \\
\hline Remained stable & 9.8 \\
\hline Decreased up to $25 \%$ & 7.6 \\
\hline Decreased 25 to $50 \%$ & 16.7 \\
\hline Decreased 50 to $75 \%$ & 19.6 \\
\hline Decreased $>75 \%$ & 46.2 \\
\hline \multicolumn{2}{|l|}{ Telemedicine implementation } \\
\hline Yes & 28.1 \\
\hline No & 71.9 \\
\hline
\end{tabular}

* i.e. vasectomy, circumcision, hydrocelectomy

** i.e. transurethral resection of prostate, transurethral resection of bladder tumor, ureterolithotripsy

*** i.e. oncological, laparoscopic surgeries, kidney transplantation 
Table 2 - Impact on educational activities during COVID-19.

\begin{tabular}{lc}
\hline Educational and scientific activities cancelled durin COVID-19 & $\%$ \\
\hline General urology department grand rounds & 53.8 \\
Subspecialty conference & 25.8 \\
Interdisciplinary conference & 29.1 \\
Morbidity and mortality meeting (M\&M) & 16.0 \\
Core Curriculum lecture & 38.5 \\
Journal clubs meeting & 26.2 \\
Bedside clinical teaching & 54.2 \\
Educational and scientific activities developed during COVID-19 & $\%$ \\
None & 10.9 \\
Case based discussion webmeeting & 68.3 \\
Subspecialty webconference & 40.7 \\
Pre-recorded video lectures & 56.0 \\
Online courses & 17.4 \\
Journal clubs webmeeting & 54.9 \\
Online general urology department grand rounds & 60.0 \\
\hline
\end{tabular}

Figure 1-a) Damage to urological learning in 2020 as estimated by residents from postgraduate years 3,4 and 5 and b) Percentage of residents from postgraduate years 3,4 and 5 who favor extending the residency program
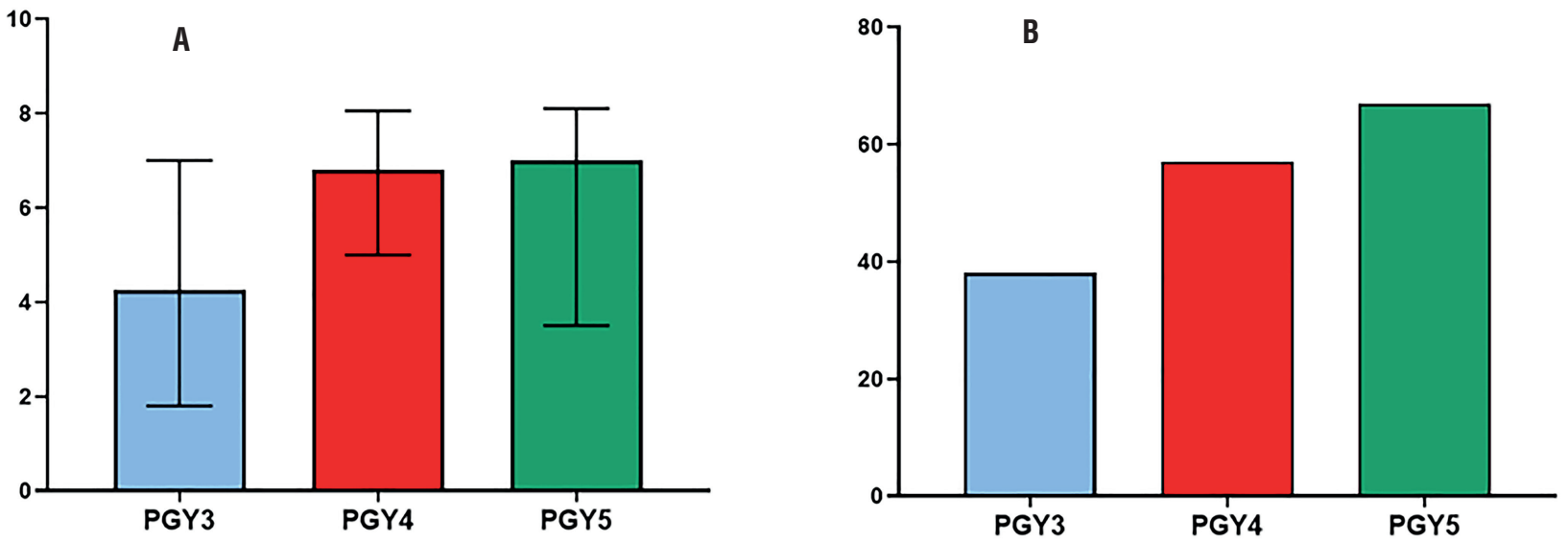

PGY3: Postgraduate year 3; PGY4: Postgraduate year 4; PGY5: Postgraduate year 5 
Table 3 - Health parameters during COVID-19.

\begin{tabular}{ll}
\hline Health parameters & $\%$ \\
\hline Weight & 14.6 \\
Reduced & 41.6 \\
Stable & 43.8 \\
Increased & \\
Physical activity & 68.6 \\
Reduced & 20.4 \\
Stable & 10.9 \\
Increased & \\
Alcoholic beverages intake & \\
Reduced & 14.1 \\
Stable & 41.0 \\
Increased & 44.9 \\
Satisfaction with sexual life & \\
Satisfied & 25.2 \\
Neither satisfied nor dissatisfied & 59.5 \\
Dissatisfied & 15.3 \\
Sexual life during CoviD-19 (compared to pre-CoVID-19) & \\
Worsened & 25.2 \\
Unchanged & 59.5 \\
Improved & 15.3 \\
\hline
\end{tabular}

${ }^{*}$ participants who reported not drinking alcoholic beverages were removed from calculations

ges, increased consumption was reported by $44.9 \%$. A total of 169 (61.68\%), 44 (16.06\%) and 61 (22.26\%) considered themselves satisfied, neither satisfied nor dissatisfied and dissatisfied with their sexual life, respectively. In comparison with their pre-pandemic sexual life, 163 (59.5\%) subjects reported their sexual life remained stable, 69 (25.2\%) reported it became worse and 42 (15.3\%) reported an improvement. Feelings of sadness or depression were reported as at least sometimes by 87 (31.7\%) and frequent by 45 $(16.5 \%)$ residents.
In June/2020, 67 (24.4\%) of Brazilian urology residents had had COVID-19, including 18.6\% with unequivocal laboratory confirmation and 5.8\% with a diagnosis based on clinical, epidemiological and radiological parameters. In all instances, the clinical presentation was mild or moderate and none required hospitalization. Also, 135 (49.3\%) had been summoned up to work in the front-line treatment of COVID-19 patients. Of those directly involved in the treatment of patients infected by SARS-CoV-2,70 (25.4\%) reported receiving adequate training to work 
with such patients while 103 (37.7\%) and 100 (36.6\%) reported inadequate or no training, respectively.

Regarding the support received from their staff/mentors during the pandemics, 140 (51.1\%) of the participants were satisfied or very satisfied, 78 $(28.5 \%)$ were neither satisfied nor dissatisfied and 56 (20.4\%) were dissatisfied or very dissatisfied.

Among the concerns regarding being infected with SARS-CoV-2, the risk of contaminating family members was reported by 234 (85.7\%) residents, being away from the residency program and fail to complete their training by 174 (63.7\%), developing COVID-19 by 129 (47.2\%), being away from hospital and overloading their colleagues by 114 (41.7\%) and being summoned up to work in the front line by 53 (19.4\%) residents. Fifty-two (19.0\%) residents changed their housing to self-isolate and avoid the risk of transmitting the disease to a family member. A shortage of PPE was reported by most residents, including N-95 masks by 124 (61.4\%) residents, waterproof apron by 101 (50.8\%), protective glasses or face shield by $80(42.2 \%)$ surgical masks by 54 (28.4\%) and caps by 39 (20.3\%) residents.

\section{DISCUSSION}

We have shown a massive impact of $\mathrm{CO}$ VID-19 on urology residents' clinical practice and education, regardless of the post graduate year or whether they train in a state among the highest or lowest incidence of COVID-19. They have all experienced the cessation or postponement of elective and preventive consultations, diagnostic procedures and non-emergency surgeries. Training was thus severely impaired and junior residents were less worried about their education breach, having evaluated the damage to their training as significantly less severe than PGY 4 and 5 residents. Moreover, significant changes in health and lifestyle were observed, with a great proportion of residents considering themselves not healthy $(46.2 \%)$, reporting feelings of sadness or depression (48.2\%), reporting weight gain (43.8\%), reduction of physical activities (68.6\%), increased alcoholic intake (44.9\%) and decreased satisfaction with sexual life (25.2\%). Finally, almost half of Brazilian urology residents had been summoned up to work in the front-line treatment of COVID-19 patients and 24.4\% had acquired CO-
VID-19 at the time of the survey.

Our study was performed in June/2020, when Brazil ranked second among the countries with the highest number of deaths due to COVID-19 in the world $(12,13)$. As we finish the preparation of this manuscript, in early December/2020, Brazil has maintained a very high incidence of COVID-19 and is experiencing a second wave as many countries worldwide (13). Governmental guidelines supporting economy closure or reopening and social distancing have varied during the year and a return to more restrictive recommendations is evolving in response to the second wave of the pandemics. As a result, a sustained detrimental impact on residents' training is to be expected.

A total of 458 eligible Brazilian urology residents received a link to the survey, of which 275 (58.7\%) participated. Because we gave no incentives to participants and we used a long questionnaire (39 questions), we consider our participation rate as very good, and in line with recent online surveys evaluating medical residents, in which participation rates varied from $45 \%$ to $60.8 \%(3,4)$.The distribution of respondents was in accordance with the actual distribution of residents throughout the different states of the country and also regarding gender and the post graduate year, confirming a well-balanced and representative participant distribution.

We observed a greater than 50\% reduction in elective patient visits, diagnostic procedures, elective surgeries and in 22.9\% of urgent consultations. Residents from different PGY were similarly affected. In a study that evaluated the impact of COVID-19 in Italian residents, a severe reduction $(>40 \%)$ or complete suppression $(>80 \%)$ of training exposure ranged between $41.1 \%$ and $81.2 \%$ for "clinical" activities and between 44.2\% and $62.1 \%$ for "surgical" activities (3). The reductions were more pronounced for residents who attended the last year of training. This possibly reflects the heterogeneity of urological training in various residency programs or different policies for restriction of surgical procedures in the two countries. Although the impact on training has been profound among all residents in Brazil, PGY 4 and 5 residents reported more severe damage to their education, which may reflect the perceived opportunity of PGY 3 urology residents to com- 
pensate for their educational losses in the following two years of residency.

Urology residency programs cancelled most educational/scientific in-person activities and developed a number of online educational programs including case based discussion and journal club web meetings, subspeciality web conference, pre-recorded video lectures, online courses and online general urology department grand rounds. $(7,14)$ Furthermore, local, national, and international societies have implemented various educational activities such as webinars with ample access to participants that have also contributed to mitigate residents' educational curtailment $(6,15,16)$.

Although online activities have served as a strong tool for medical education since the beginning of the pandemics, people are getting exhausted with this format (17). Being on a video call or teleconference requires more focus than face-to-face meetings and lectures because it is harder to process non-verbal cues like facial expressions, the tone and pitch of the voice, and body language (17). In addition, many of us are using video calls at work, family celebrations and interaction with friends. Everything seems to be happening in the same place, which further contributes to negative feelings for online meetings. Moreover, the online meetings remind us of the people, opportunities, and lifestyle that we have lost temporarily.

A significant impact was observed in several health indicators of urology residents. Almost half of the participants considered themselves moderately healthy $(19.6 \%)$ or not healthy $(26.6 \%)$. The mental afflictions resulting from the COVID pandemic may have an important role in this self-reported perception of general well-being as well as in the high rates of depressive feelings reported. Similar findings have been observed with French urology residents, of whom 56.5\% reported medium to high levels of stress (8). A survey with American urology residents demonstrated that perception of access to personal protection equipment, local COVID-19 severity and perception of susceptible household members are important risk factors of mental health outcomes (18). All of these risk factors were present among Brazilian urologists.

To protect their families, many healthcare providers have chosen to isolate themselves (19). In our study, 20.0\% of urology residents changed their housing status, to avoid transmitting COVID-19 to a family member. Home confinement is also a factor that might influence alcohol misuse, physical and sexual activity (20-23). A significant decrease of physical activity has been shown in the general population during the COVID-19 pandemic (9). In the present study, $68.6 \%$ of the participants reported reduced physical activity. Many reported weight gain (43.8\%) while $14.6 \%$ had weight loss. Increased alcoholic intake during the COVID-19 pandemic was reported by $44.9 \%$ of the urology residents, which was much higher than the $17.6 \%$ increase observed in the general adult Brazilian population (9). A similar finding occurred regarding tobacco consumption, which increased for 53.4\% of the smoking participants while only $34.0 \%$ of the smokers in the general Brazilian population reported increased tobacco consumption during the pandemic (9). These numbers are alarming and may reflect the increased distress caused by the pandemic among health professionals.

Sexual life satisfaction is an important issue related to mental health status. A recent study with French urologists residents demonstrated that sexual intercourse is a protective factors for burnout (24). In our study, $25.2 \%$ of the urology residents reported being dissatisfied with their sexual life. Compared to pre-COVID-19 status, 25.18\% of the respondents reported a worse sexual life. Similar findings showing worsening of sexual life were found among urologists in Brazil and the general population $(5,25)$.

A clinical infection by SARS-CoV-2 was reported by $24.4 \%$ of the participants. To our knowledge, this is the first study to report on COVID-19 infection rates among urology residents and surgical residents in general. The infection rate in Brazilian urology residents seems much higher than expected and surpass the infection rate of 13.5\% reported by urologists in Brazil (5). A recent meta-analysis showed that around 10\% of healthcare personnel working in hospitals had a diagnosis of COVID-19 infection and the risk was higher among nurses.(26) In our study, none of the participants who had a clinical infection by the COVID-19 required hospitalization. This is in great contrast with the high rates of more severe COVID-9 in Brazilian urologists, among whom 34\% required hospitalization.(5) A recent meta-analyses showed a prevalence of severe COVID-19 
of 5\% among healthcare workers, while $0.5 \%$ died because of the complications of the disease (26). Certainly, the age difference between participants in the present study and the one with urologists in Brazil (median of 30 and 46.0 years, respectively) was the main reason for the observed difference in clinical severity of COVID-19 (27).

Involvement of residents in COVID-19 care varied substantially by specialty in different countries. Some may be caring for patients with COVID-19 during assigned rotations while others may be voluntarily redeployed to work with these patients. Half of the participants of the present study have been summoned up to work in the front-line care of patients with COVID-19. This is in contrast with urology and surgery residents in Italy, of whom only 7.7\% and $14.8 \%$ were moved to the front-line care of COVID-19 patients $(3,28)$. A significant proportion of participants showed preoccupations regarding being dislocated to the front-line treatment of COVID-19. Most frequent concerns were transmitting infection to family members, compromising their urological training, being infected with COVID-19 and maintenance of financial support. These concerns are in line with those reported in other studies $(28,29)$.

Only $25.4 \%$ of the respondents reported receiving adequate training to work with COVID-19 patients and most residents reported insufficient availability of PPE, including surgical masks (28.4\% of the participants), N-95 masks (61.4\%), face shield (42.2\%) and waterproof apron (50.8\%). The combination of working in the front-line care of patients with COVID-19 with inadequate training for dealing with these patients and insufficient PPE availability may have contributed to the high rate of COVID-19 infection among participants. In a recent manuscript published in the New England Journal of Medicine, Gallagher and Schleyer remind us of the personal risks health care professionals face when caring for patients with communicable diseases (29). We want to join them in praising our medical students and trainees for stepping up during the Covid-19 pandemic despite their risks and fears.

Asked about what should be done to mitigate their training breach throughout 2020, most proposed extending the training program for some months. Additional training in subspecialties was also recommended by many participants. In a study conducted in India with ophthalmology residents, eighty percent felt the pandemic had damaged their medical education and suggested that extending the residency period would be necessary $(30,31)$.

The main strengths of this study are the large number of participants, the balanced distribution of residents from different postgraduate years and the comprehensive evaluation of various aspects of medical practice, educational activities and health and lifestyle parameters, allowing us to make a reliable picture of the impact of the pandemic on urology residents in Brazil. This is the first study to report on COVID-19 infection rates among residents of a surgical specialty. The cross-sectional design, providing an evaluation of a single snapshot in time is a limitation of the study. As the pandemics has assumed different faces throughout the year, residents' mood and perceptions may certainly fluctuate with time. The questionnaire is long, which may make participants bored through the process of answering it. Nevertheless, the response rates were very high. Another point is that the instruments used to evaluate many of the parameters are not validated. For instance, mental health was assessed using a single question, instead of a validated questionnaire. Despite these limitations, our findings seem to present a reliable picture of the impact of COVID-19 in a number of aspects of Brazilian urology residents' education, health and lifestyle behavior than can possibly be expanded for residents from other medical specialties. Further studies should confirm these findings and expand on the evaluation of the detrimental impacts of COVID-19 in medical residents from different specialties to help developing strategies to mitigate their losses.

\section{CONCLUSION}

COVID-19 had a massive impact on Brazilian urology residents' clinical practice and education. Training was severely impaired and junior residents perceived the damage to their education as less severe than senior residents. Significant changes in health and lifestyle were observed, with many residents reporting weight gain, reduced physical activity, increased alcoholic intake and cigarette consumption, worsening of sexual life and feelings of sadness or depression. Finally, almost half of Brazilian urology residents had been summoned to work on the front- 
-line treatment of COVID-19 patients and a quarter had acquired COVID-19 at the time of the survey.

\section{ACKNOWLEDGEMENTS}

The authors would like to thank the participants of the study for their time. This study received no funding.

\section{CONFLICT OF INTEREST}

Cristiano M. Gomes

Grant/Research study: Ipsen; Consultancy: Astellas Pharma, Boston Scientifics, Coloplast, Medtronic; Apsen

Lectures: Astellas, Boston Scientific, Zodiac,

Other authors have no conflict of interest

\section{REFERENCES}

1. Ficarra V, Novara G, Abrate A, Bartoletti R, Crestani A, De Nunzio C, et al. Urology practice during the COVID-19 pandemic. Minerva Urol Nefrol. 2020;72:369-75.

2. Carneiro A, Wroclawski ML, Nahar B, Soares A, Cardoso AP, Kim NJ, et al. Impact of the COVID-19 Pandemic on the Urologist's clinical practice in Brazil: a management guideline proposal for low- and middle-income countries during the crisis period. Int Braz J Urol. 2020;46:501-10.

3. Amparore D, Claps F, Cacciamani GE, Esperto F, Fiori C, Liguori $G$, et al. Impact of the COVID-19 pandemic on urology residency training in Italy. Minerva Urol Nefrol. 2020;72:505-9.

4. Rosen GH, Murray KS, Greene KL, Pruthi RS, Richstone L, Mirza M. Effect of COVID-19 on Urology Residency Training: A Nationwide Survey of Program Directors by the Society of Academic Urologists. J Urol. 2020;204:1039-45.

5. Gomes CM, Favorito LA, Henriques JVT, Canalini AF, Anzolch KMJ, de Carvalho Fernandes R, et al. Impact of COVID-19 on clinical practice, income, health and lifestyle behavior of Brazilian urologists. Int Braz J Urol. 2020;46.

6. Kwon YS, Tabakin AL, Patel HV, Backstrand JR, Jang TL, Kim IY, et al. Adapting Urology Residency Training in the COVID-19 Era. Urology. 2020;141:15-9.

7. Chan EP, Stringer L, Wang PZT, Dave S, Campbell JD. The impact of COVID-19 on Canadian urology residents. Can Urol Assoc J. 2020;14:E233-6.
8. Abdessater M, Rouprêt M, Misrai V, Matillon X, GondranTellier B, Freton L, et al. COVID19 pandemic impacts on anxiety of French urologist in training: Outcomes from a national survey. Prog Urol. 2020;30:448-55.

9. Malta DC, Szwarcwald CL, Barros MBA, Gomes CS, Machado ÍE, Souza Júnior PRB, et al. The COVID-19 Pandemic and changes in adult Brazilian lifestyles: a cross-sectional study, 2020. Epidemiol Serv Saude. 2020;29:e2020407.

10. [No authors]. COVID-19 Dashboard by the Center for Systems Science and Engineering (CSSE) at Johns Hopkins University (JHU) [Internet]. 2020.

11. [No authors]. Coronavirus second wave: Which countries in Europe are experiencing a fresh spike in COVID-19 cases? [Inernet]. 2020. Available at: <https://www.euronews. com/2020/11/18/is-europe-having-a-covid-19-secondwave-country-by-country-breakdown>

12. Bean BP. Pharmacology and electrophysiology of ATPactivated ion channels. Trends Pharmacol Sci. 1992;13:87-90.

13. World Health 0. Coronavirus disease ( COVID-19) : situation report, 162. Geneva: World Health Organization. 2020.

14. Vargo E, Ali M, Henry F, Kmetz D, Drevna D, Krishnan J, et al. Cleveland Clinic Akron General Urology Residency Program's COVID-19 Experience. Urology. 2020;140:1-3.

15. Smigelski M, Movassaghi M, Small A. Urology Virtual Education Programs During the COVID-19 Pandemic. Curr Urol Rep. 2020;21:50.

16. Campi R, Amparore D, Checcucci E, Claps F, Teoh JY, Serni S, et al. Exploring the Residents' Perspective on Smart learning Modalities and Contents for Virtual Urology Education: Lesson Learned During the COVID-19 Pandemic. Actas Urol Esp. 2021;45:39-48.

17. [No authors]. The reason Zoom calls drain your energy. BBC; [Internet]. Available at: <https://www.bbc.com/ worklife/article/20200421-why-zoom-video-chats-are-soexhausting >

18. Khusid JA, Weinstein CS, Becerra AZ, Kashani M, Robins DJ, Fink LE, et al. Well-being and education of urology residents during the COVID-19 pandemic: Results of an American National Survey. Int J Clin Pract. 2020;74:e13559.

19. Xiang YT, Yang Y, Li W, Zhang L, Zhang Q, Cheung T, et al. Timely mental health care for the 2019 novel coronavirus outbreak is urgently needed. Lancet Psychiatry. 2020;7:228-9.

20. Peçanha T, Goessler KF, Roschel H, Gualano B. Social isolation during the COVID-19 pandemic can increase physical inactivity and the global burden of cardiovascular disease. Am J Physiol Heart Circ Physiol. 2020;318:H1441-6.

21. Rodriguez LM, Litt DM, Stewart SH. Drinking to cope with the pandemic: The unique associations of COVID-19-related perceived threat and psychological distress to drinking behaviors in American men and women. Addict Behav. 2020;110:106532. 
22. Lopes GP, Vale FBC, Vieira I, da Silva Filho AL, Abuhid C, Geber S. COVID-19 and Sexuality: Reinventing Intimacy. Arch Sex Behav. 2020;49:2735-8.

23. Turban JL, Keuroghlian AS, Mayer KH. Sexual Health in the SARS-CoV-2 Era. Ann Intern Med. 2020;173:387-9.

24. Gas J, Bart S, Michel P, Peyronnet B, Bergerat S, Olivier J, et al. Prevalence of and Predictive Factors for Burnout Among French Urologists in Training. Eur Urol. 2019;75:702-3.

25. Arafat SMY, Alradie-Mohamed A, Kar SK, Sharma P, Kabir R. Does COVID-19 pandemic affect sexual behaviour? A crosssectional, cross-national online survey. Psychiatry Res. 2020;289:113050.

26. COVID-19 in Healthcare Workers: A Living Systematic Review and Meta-analysis of Prevalence, Risk Factors, Clinical Characteristics, and Outcomes

27. Romero Starke K, Petereit-Haack G, Schubert M, Kämpf D, Schliebner A, Hegewald J, et al. The Age-Related Risk of Severe Outcomes Due to COVID-19 Infection: A Rapid Review, Meta-Analysis, and Meta-Regression. Int J Environ Res Public Health. 2020;17:5974.

28. Pertile D, Gallo G, Barra F, Pasculli A, Batistotti P, Sparavigna $\mathrm{M}$, et al. The impact of COVID-19 pandemic on surgical residency programmes in Italy: a nationwide analysis on behalf of the Italian Polyspecialistic Young Surgeons Society (SPIGC). Updates Surg. 2020;72:269-80.
29. Gallagher TH, Schleyer AM. "We Signed Up for This!" Student and Trainee Responses to the Covid-19 Pandemic. N Engl J Med. 2020;382:e96.

30. Mishra D, Nair AG, Gandhi RA, Gogate PJ, Mathur S, Bhushan $P$, et al. The impact of COVID-19 related lockdown on ophthalmology training programs in India - Outcomes of a survey. Indian J Ophthalmol. 2020;68:999-1004.

31. Paesano N, Santomil F, Tobia I. Impact of COVID-19 Pandemic on Ibero-American Urology Residents: Perspective of American Confederation of Urology (CAU). Int Braz J Urol. 2020 Jul;46(suppl.1):165-9.

Correspondence address:

Cristiano Mendes Gomes, MD

Divisao de Clinica Urologica

Hospital das Clinicas da Universidade de São Paulo Av. Dr. Eneas de Carvalho Aguiar, 255 - Sala 710F

São Paulo, SP, 05403-000, Brasil

Fax: + 5511 3064-7013

E-mail: crismgomes@uol.com.br 
APPENDIX

\section{Supplementary Questionnaire: COVID-19 Impact Questionnaire on Urology Residents in Brazil}

1. Consent form: You are invited to participate as a volunteer, in a study developed by the Brazilian Society of Urology (SBU). In case you agree to be part of the research, after reading this Consent Form, tick ACCEPTED at the end of this document. If you do not wish to participate, just tick on I DO NOT ACCEPT.

This is a study to understand how COVID-19 has affected Urology Residents throughout Brazil. It consists of a survey with questions regarding various educational, professional and personal aspects. Completion of this questionnaire should take approximately 10 minutes. We believe this research can help develop strategies to minimize or reverse the damage to your urological formation resulting from COVID-19.

The answered survey shall be filed in a restricted access database, with no identification of the respondent. Participation is voluntary and confidentiality is guaranteed. The material collected in the research may be used in future publications either in a book, scientific journals, SBU journals or digital communications. The study will not bring any risk to you or offer any financial advantage.

For any further questions, please contact the researchers by e-mail: sbuonline@sbunet. org.br.

\section{CONSENT TO PARTICIPATE IN THE RESEARCH}

I was duly informed and clarified by the researchers about the study, the procedures involved as well as the possible risks and benefits arising from my participation.

o I ACCEPT to participate in the research

o I DO NOT ACCEPT to participate in the research 
2. How old are you?

3. What year of Urology Residency are you in?

- R1 - 1st year Resident in Urology

- R2 - 2nd year Resident in Urology

- R3 - 3rd year Resident in Urology

4. In which Brazilian state do you attend your Urology Residency?

\begin{tabular}{|c|c|}
\hline 0 & Acre \\
\hline & Alagoas \\
\hline 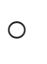 & Amapá \\
\hline D & Amazonas \\
\hline D & Bahia \\
\hline & Ceará \\
\hline & Distrito Federal \\
\hline & Espírito Santo \\
\hline ) & Goiás \\
\hline D & Maranhão \\
\hline o & Mato Grosso \\
\hline o & Mato Grosso do Sul \\
\hline o & Minas Gerais \\
\hline o & Pará \\
\hline o & Paraíba \\
\hline O & Paraná \\
\hline O & Pernambuco \\
\hline O & Piauí \\
\hline O & Rio de Janeiro \\
\hline ○ & Rio Grande do Norte \\
\hline ० & Rio Grande do Sul \\
\hline O & Rondônia \\
\hline O & Roraima \\
\hline 0 & Santa Catarina \\
\hline o & São Paulo \\
\hline b & Sergipe \\
\hline & Tocantins \\
\hline
\end{tabular}


5. Which of the following options best describe the institution you attend your Residency?

- Public University Hospital

- Private University Hospital

- Non-university Public Hospital

○ Private non-university Hospital

6. As for the size, the institution where you take up Urology Residency may be classified as:

S Small: holds a capacity of less than or equal to 50 beds;

- Medium: offers 51 to 150 beds;

○ Large: holds from 151 to 500 beds;

- Special or extra size: offers more than 500 beds.

7. I am:

○ Male

- Female

8. Do you receive resident grant?

- Yes

○ No

9. Which of the following do you use for income supplementation? (more than one answer is allowed)

- I live only off my medical residency scholarship

- Shifts as a clinician or surgeon

- Other medical activities other than urology

- Assistance to urology teams aside from the scope of residency

- Activities other than medicine

- Family or third-party assistance 
10. Compared to the average of the 3 months preceding the COVID-19 pandemic, your income in the last 4 weeks (since the beginning of the pandemic):

- Remained stable

- Was reduced by up to $25 \%$

- Was reduced between 25 and $50 \%$

- Was reduced between 50 and $75 \%$

- Was reduced by more than $75 \%$

- Increased by more than $10 \%$

11. Compared to the average of the 3 months preceding the COVID-19 pandemic, the number of urological elective consultations you have performed/participated in since the beginning of the pandemic:

- Remained stable

- Was reduced by up to $25 \%$

- Was reduced between 25 and $50 \%$

- Was reduced between 50 and $75 \%$

- Was reduced by more than $75 \%$

12. Compared to the average of the 3 months preceding the COVID-19 pandemic, the number of urological emergency consultations (First Aid inter-consultations) you have performed/ participated since the beginning of the pandemic:

- Remained stable

- Was reduced by up to $25 \%$

- Was reduced between 25 and 50\%

- Was reduced between 50 and $75 \%$

- Was reduced by more than $75 \%$ 
13. Compared to the average of the 3 months preceding the COVID-19 epidemic, the number of small urological elective surgeries (e.g., postectomy, vasectomy, hydrocele) you have performed/participated since the beginning of the pandemic:

- Remained stable

- Was reduced by up to $25 \%$

- Was reduced between 25 and $50 \%$

- Was reduced between 50 and $75 \%$

- Was reduced by more than $75 \%$

14. Compared to the average of the 3 months preceding the COVID-19 pandemic, the number of diagnostic procedures (e.g., cystoscopy, prostate biopsy) you have performed/participated since the beginning of the pandemic:

- Remained stable

- Was reduced by up to $25 \%$

- Was reduced between 25 and $50 \%$

- Was reduced between 50 and $75 \%$

- Was reduced by more than $75 \%$

15. Compared to the average of the 3 months preceding the COVID-19 pandemic, the number of endoscopic surgeries (e.g., transurethral resection of the prostate or bladder, endoscopic ureterolitotripsy) you have performed/participated since the beginning of the pandemic:

- Remained stable

- Was reduced by up to $25 \%$

- Was reduced between 25 and $50 \%$

- Was reduced between 50 and $75 \%$

- Was reduced by more than $75 \%$ 
16. Compared to the average of the 3 months preceding the COVID-19 pandemic, the number of major surgeries (e.g., laparoscopic, oncological, kidney transplantation) you have performed/participated since the beginning of the pandemic:

○ Remained stable

- Was reduced by up to $25 \%$

- Was reduced between 25 and $50 \%$

- Was reduced between 50 and $75 \%$

- Was reduced by more than $75 \%$

17. Since the beginning of the pandemic, has your urology service implemented some kind of teleconsultation platform to replace face-to-face care?

- Yes

○ No

18. Due to the COVID-19 pandemic, which in person educational / scientific activities within your residency you no longer have? (more than one answer is allowed)

- General urology department grand rounds

o Subspecialty conference

o Interdisciplinary conference

o Morbidity and mortality meeting (M\&M)

o Core Curriculum lecture

o Journal clubs meeting

o Bedside clinical teaching 
19. Due to the COVID-19 pandemic restrictions, what educational/scientific activities have been implemented by your residency program to make up for the damage to your urological training? (more than one answer is allowed)

o None

- Case based discussion webmeeting

o Subspecialty webconference

o Pre-recorded video lectures

o Online courses

o Journal clubs webmeeting

o Online general urology department grand rounds

20. To make up for the educational losses resulting from the COVID-19 pandemic, please order, according to your preference, among the following modalities of online educational programs:

- Video-conference courses/classes

- Interactive discussions of clinical cases or practical aspects

- Didactic content in podcast format

21. How satisfied are you with your current health?

○ Very dissatisfied

- Dissatisfied

- Neither satisfied/nor dissatisfied

○ Satisfied

- Very satisfied 
22. How often have you felt sad or depressed?

- Never

- Rarely

- Sometimes

- Often

○ Very often

23. Since the beginning of the pandemic, your weight:

- Remained stable

- Decreased

- Increased

24. Regarding the practice of PHYSICAL ACTIVITIES since the beginning of the COVID-19 pandemic:

- Remained stable

- Decreased

○ Increased

25. Regarding the consumption of ALCOHOLIC BEVERAGES since the beginning of the COVID-19 pandemic:

- Do not consume alcoholic beverages

o Remained stable

o Decreased

o Increased 
26. Regarding SMOKING HABITS since the beginning of the COVID-19 pandemic:
o Do not smoke
o Remained stable
o Decreased
o Increased

27. How satisfied are you with your SEX LIFE at the moment?

○ Very dissatisfied

○ Dissatisfied

- Neither satisfied/nor dissatisfied

- Satisfied

○ Very satisfied

28. Compared to the average of the 3 months preceding the COVID-19 pandemic, your sex life:

- Remained stable

- Got worse

- Improved

29. What are your concerns regarding COVID-19? (more than one answer is allowed)

- I have no worries, since I believe in case I am infected I won't develop a serious form of the disease

- To develop serious illness

- To contaminate my family members

- To be called to work on the front line care

- To need to get away from work and lower my income

- To need to move far away from the residency and compromise my training

○ To need to move far away from the residency and overwhelm my colleagues 
30. How concerned are you about the possibility of having to work on the front line care for patients with COVID-19?

○ Very worried

- Moderately concerned

- A little worried

- Not worried

31. In the context of your UROLOGY RESIDENCY, have you been displaced to work on the front line care for patients with COVID-19 (emergency care shift, infirmary shift, ICU shift)?

○ Yes

○ No

32. Considering health authorities recommendations for the use of personal protective equipment (PPE) for care during the COVID-19 pandemic, which of the following items do you consider insufficient in the hospital you act as a resident? (More than one answer is allowed)

- Surgical mask

- N-95 mask

- Goggles or face shield

- Waterproof apron

- Cap

33. How was your training for the care of patients with COVID-19 in the context of your residence?

- I received adequate face-to-face or online training

- I received little face-to-face or online training

- I have not received any face-to-face or online training

34. Compared to the period prior to COVID-19, how do you feel about the support you have received from the head of your residency and the assistants/preceptors?

- Very dissatisfied

- Dissatisfied

- Neither satisfied/nor dissatisfied

- Satisfied

- Very satisfied 
35. Have you had symptomatic coronavirus infection?

- Yes, with unambiguous confirmation (laboratory, tomography or other)

- Likely (suspected clinical and epidemiological picture, but did not have confirmation tests)

- Unlikely (unsuspected clinical and epidemiological picture)

○ No

36. In case you had symptomatic coronavirus infection, what was the severity of the clinical presentations?

- I didn't have any

- Mild clinical presentations

- Moderate clinical presentations, no need for hospitalization

- Severe clinical presentations, requiring hospitalization

- Severe clinical presentations, requiring ICU admission

37. If you had or have symptomatic coronavirus infection in need of hospitalization, where did you or would you seek treatment?

- Hospital where I attend my residency

- SUS (Public Health plan) Reference Hospital

- Private network hospital

38. During the COVID-19 pandemic and in the face of the risk of contaminating your family members, have you changed your housing habits?

- I don't have that concern since I live alone

- I still live in the same place despite the risks

- I still live in the same place but I asked my family members to move elsewhere

- I moved out of my house 
39. In case the activities of the urology residency remain compromised for a period of 6 months or longer as a consequence of the COVID-19 pandemic, what measures would you like to be instituted in order to make up for the damage to your training?

$\circ$ Extension of the completion of the residency in some months

- One extra year of residency

- Offering of internships in the deficient areas

$\circ$ I do not find the need of any additional training period 